\title{
Effect of Spatial Disorientation in a Virtual Environment on Gait and Vital Features in Patients with Dementia: Pilot Single-Blind Randomized Control Trial
}

\author{
Chimezie O Amaefule ${ }^{1}$, MSc; Stefan Lüdtke ${ }^{2}$, MSc; Thomas Kirste ${ }^{2}$, DEng; Stefan J Teipel ${ }^{1,3}$, DMed \\ ${ }^{1}$ German Center for Neurodegenerative Diseases (DZNE), Rostock, Germany \\ ${ }^{2}$ Institute of Visual \& Analytic Computing, University of Rostock, Rostock, Germany \\ ${ }^{3}$ Department of Psychosomatic and Psychotherapeutic Medicine, University Medicine Rostock, Rostock, Germany
}

Corresponding Author:

Chimezie O Amaefule, MSc

German Center for Neurodegenerative Diseases (DZNE)

Gehlsheimer Strasse 20

Rostock, 18147

Germany

Phone: 493814949478

Fax: 493814949472

Email: chimezie.amaefule@dzne.de

\begin{abstract}
Background: Orientation deficits are among the most devastating consequences of early dementia. Digital navigation devices could overcome these deficits if adaptable to the user's needs (ie, provide situation-aware, proactive navigation assistance). To fulfill this task, systems need to automatically detect spatial disorientation from sensors in real time. Ideally, this would require field studies consisting of real-world navigation. However, such field studies can be challenging and are not guaranteed to cover sufficient instances of disorientation due to the large variability of real-world settings and a lack of control over the environment.

Objective: Extending a foregoing field study, we aim to evaluate the feasibility of using a sophisticated virtual reality (VR) setup, which allows a more controlled observation of disorientation states and accompanying behavioral and physiological parameters in cognitively healthy older people and people with dementia.
\end{abstract}

Methods: In this feasibility study, we described the experimental design and pilot outcomes of an ongoing study aimed at investigating the effect of disorientation on gait and selected physiological features in a virtual laboratory. We transferred a real-world navigation task to a treadmill-based virtual system for gait analysis. Disorientation was induced by deliberately manipulating landmarks in the VR projection. Associated responses in motion behavior and physiological parameters were recorded by sensors. Primary outcomes were variations in motion and physiological parameters, frequency of disorientation, and questionnaire-derived usability estimates (immersion and perceived control of the gait system) for our population of interest. At this time, the included participants were 9 cognitively healthy older participants [5/9 women, 4/9 men; mean age 70 years, SD 4.40; Mini-Mental State Examination (MMSE) mean 29, SD 0.70) and 4 participants with dementia (2/4 women, 2/4 men; mean age 78 years, SD 2.30 years; MMSE mean 20.50, SD 7.54). Recruitment is ongoing, with the aim of including 30 cognitively healthy older participants and 20 participants with dementia.

Results: All 13 participants completed the experiment. Patients' route was adapted by shortening it relative to the original route. Average instances of disorientation were $21.40,36.50$, and 37.50 for the cognitively healthy older control, cognitively healthy older experimental participants, and participants with dementia, respectively. Questionnaire outcomes indicated that participants experienced adequate usability and immersion; 4.30 for presence, 3.73 for involvement, and 3.85 for realism of 7 possible points, indicating a good overall ability to cope with the experiment. Variations were also observed in motion and physiological parameters during instances of disorientation.

Conclusions: This study presents the first feasibility outcomes of a study investigating the viability of using a sophisticated VR setup, based on an earlier real-world navigation study, to study spatial disorientation among cognitively healthy older people and people with dementia. Preliminary outcomes give confidence to the notion that our setup can be used to assess motion and physiological markers of disorientation, even in people with cognitive decline. 
Trial Registration: ClinicalTrials.gov; https://clinicaltrials.gov/ct2/show/NCT04134806

(JMIR Serious Games 2020;8(4):e18455) doi: $\underline{10.2196 / 18455}$

\section{KEYWORDS}

spatial disorientation; activity recognition; wayfinding; wearable sensors; dementia; virtual reality; older adults

\section{Introduction}

\section{Background}

Challenges in wayfinding and orientation are early symptoms of people with mild cognitive impairment (MCI) or dementia. These deficits decrease mobility [1,2] and social interaction $[3,4]$ of the affected people, which in turn may lead to further cognitive decline. Assistive technology devices (ATDs) can help reduce the burden of spatial disorientation by providing interventions (eg, by giving cues to the patients). For patients with cognitive impairment, an ideal ATD should fulfill 2 requirements: It should be situation-adaptive (ie, the device adapts to the situation and context, including the environment, user goal, and intention), and it should be subsidiary (ie, the device delivers assistance only in case of need, for example, if the user is disoriented). These requirements ensure that the device does not replace but rather leverages existing cognitive capabilities [5]. Technically, this means that the ATD needs to be able to detect instances of disorientation in real time from the available sensor data, like accelerometric, electrodermal (EDA), or electrocardiographic (ECG) data.

In a previous field study-Situation-Aware Navigation Assistance for Dementia Patients using Causal Behavior Models (SiNDeM) [6] - concerned with wayfinding behavior in MCI and patients with dementia through an urban environment, a machine learning classifier for disorientation based solely on accelerometric data led to a cross-validated area under the receiver operating characteristics curve (AUC) value of 0.75 . The outcome of this study suggested that instantaneous detection of disorientation may, in principle, be possible; however, the accuracy was not sufficient to serve as a basis for individual support. Hence, additional signals, such as heart rate variability, may be needed to increase detection accuracy. However, performing such a study in a real-world environment requires a large effort in staff and resources. One of the limitations highlighted in the previous study [6] was that the recorded number of disorientation instances per subject was low, which can be problematic when training machine learning classifiers. This is due to the fact that, firstly, the experimenter could not influence whether (and when) subjects became disoriented. Secondly, the high level of inconsistency in the real-world environment did not enable the controlled observation of disorientation states that are not induced by experimental manipulation (eg, changing of landmarks) but rather by cognitive deficits, as in the case of the patients. Thus, a large effort is required to obtain only a small amount of data related to disorientation instances (which is the data that is most relevant in this context). A more robust approach to modeling real-time disorientation might rely on both a controlled environment as well as other more informative parameters in addition to motion. Gait features have recently been vastly explored as motion markers of disease progression [7-9] and fall detection [10], and could also be informative in identifying behavioral variations predictive of disorientation. Additionally, physiological parameters, including skin conductance response and heart rate variations, have also been previously shown to be influenced by the occurrence of spatial disorientation [11,12].

As an alternative to real-world studies, navigation tasks can be posed in a virtual-reality (VR) environment $[13,14]$. However, most experimental setups do not integrate a physical component-participants sit in front of a computer screen, and thus the physical manifestation of disorientation cannot be assessed. More generally, the need for physical locomotion might influence navigation behavior, as participants are in a dual-task situation where they have to simultaneously walk and navigate through the environment. Such dual-task conditions require cognitive resources such as attentional flexibility, which are depleted as disease progresses [15-18]. Therefore, a pertinent question would be, how can the navigation task be transferred to a safe and controllable VR environment while the participants still have to walk actively (like they would do in the real world), to allow for the investigation of the relationship between disorientation and physical motion? To this extent, we propose a VR-based experimental setup that allows realistic physical movement.

Specifically, we employed the GRAIL (Gait Real-time Analysis Interactive Lab; Motekforce Link) system, providing the opportunity to navigate on a treadmill through a virtual environment. Using such a virtual environment has several advantages: The setup is safe for the subjects, reproducible, and the experimental effort per subject is lower compared to a real-world study. Furthermore, the experimenters have full control over the environment; for example, the environment can be manipulated to induce disorientation to record a larger amount of disorientation instances. Also, disorientation states resulting from cognitive deficits can be properly observed.

\section{Objectives}

This study aims to evaluate the feasibility of using a complex virtual reality setup, which allows a more controlled observation of disorientation states, to study spatial disorientation among older cognitively healthy people and people with dementia, thereby validating the findings of the real-world SiNDeM study. This environment gives access to a broader set of sensor domains compared with the real-world setting, including gait, skin conductance, and heart rate variability in addition to accelerometry; it also allows for the examination of a larger sample size within a more controlled environment to build a more accurate disorientation detection and intervention model. 


\section{Research Questions}

The study is based on the following core research question: Is our setup feasible for investigating states of disorientation during active navigation among cognitively healthy older participants and people with dementia? This is motivated by the reported overall effectiveness of VR in assessing spatial navigation [19], spatial navigation memory for predementia screening [20], and improving cognitive functioning among individuals with neurocognitive disorders [21,22]. Evaluation of the feasibility of our setup is further guided by the following research questions: (1) Is the virtual environment adequately immersive? (2) Are we able to reliably induce disorientation through the manipulation of the virtual environment? (3) Do the participants feel comfortable with the walking pattern change due to our navigation mechanism? (4) Are we able to adequately measure motion and physiological parameters?

\section{Methods}

\section{Study Design and Setting}

This is a single-blind randomized experiment currently taking place in Rostock, Germany. The experiments are carried out in the Gait Real-time Analysis Interactive Lab (GRAIL; Motekforce Link; Figure 1), which is a Class I medical system (according to the Medical Device Directive 93/42/EEC) and is specially designed to ensure the safety of participants for clinical gait analysis and training. This is achieved through a safety belt and side railings, which serve to support the participant and prevent falls. The GRAIL further consists of a treadmill, a large $180^{\circ}$ projection screen, and an optical motion capturing system (Vicon Motion Systems Ltd). A virtual environment that models a city center is shown onscreen, and subjects can navigate through the environment by walking on the treadmill. Gait kinematics and kinetics, as well as spatio-temporal gait parameters, can be derived from the motion capturing data [23]. The system has been used, for example, for rehabilitation exercise [24] or for gait analysis in different settings [25-27].

Figure 1. (A) The GRAIL system, consisting of a dual-belt treadmill, $180^{\circ}$ projection surface, and optical motion capturing system (figure sourced from Motek Medical); (B) plantar figures.

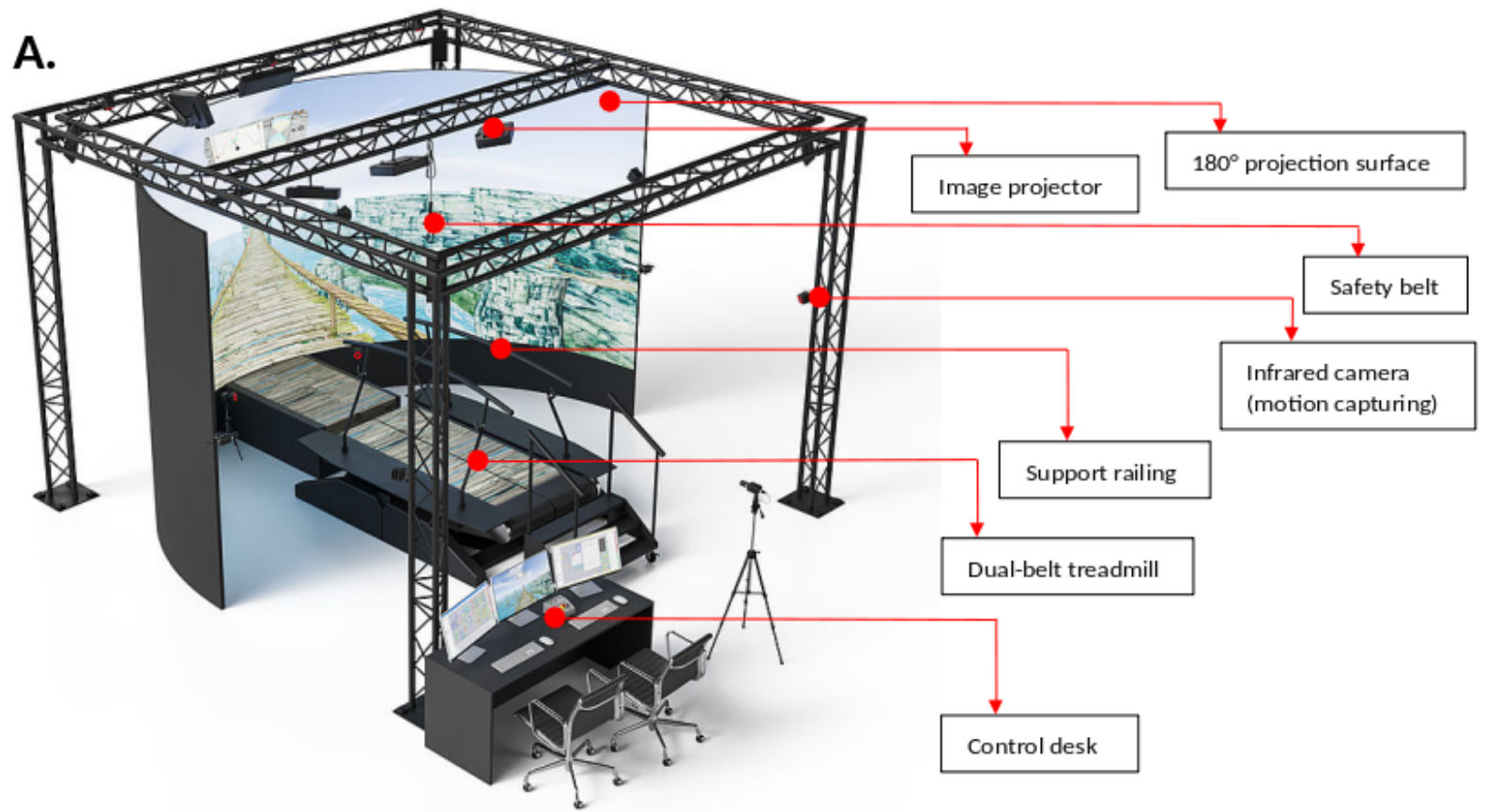

B.
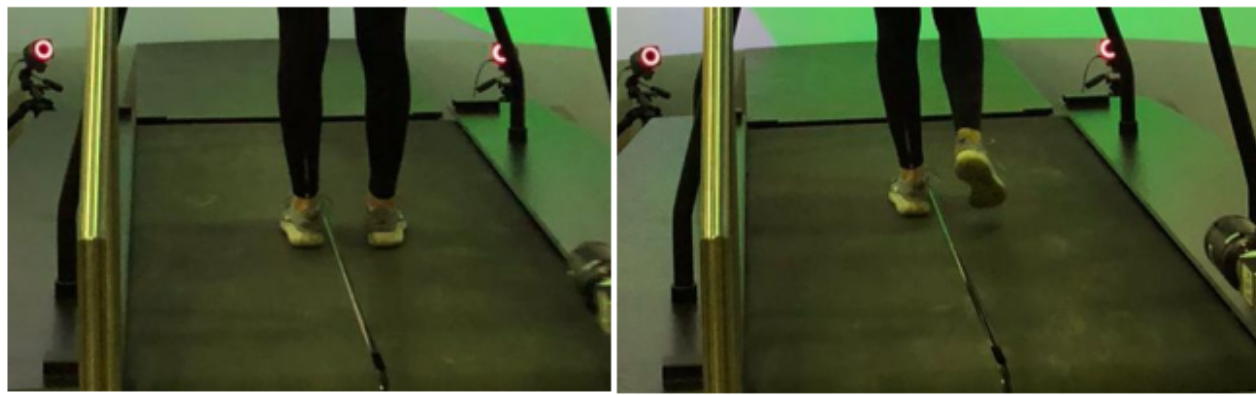

The 3D virtual environment used in this study was generated using the OSM2World tool [28]. This data includes building from OpenStreetMap (OSM) data of the Rostock city center, heights and rudimentary 3D models of landmark buildings 
(Figure 2). The resulting VR environment is a low-detail replication of the real city, but does not contain moving objects like cars or pedestrians. The treadmill speed is feedback-controlled, which allows participants to walk with their preferred walking speed. This is achieved by adapting the belt speed according to the subject position (measured by motion capturing) in relationship to the center of the belt [29]. The movement speed through the VR is synchronized with the belt speed (ie, the current speed of the participant). An important constraint of the GRAIL system is that a change in walking direction (eg, turning left or right) is not supported by the treadmill; it does not rotate. Thus, it was necessary to provide an alternative means for voluntary direction change: participants can choose their walking direction by walking on either side of the treadmill. Walking on the left side of the treadmill will result in a left turn in the VR environment, and vice versa. We are aware that this is not identical to naturalistic walking: subjects still walk a straight line on the treadmill, whereas the movement in the VR describes a curve. Therefore, as part of the current study reports, we observed the movement behavior of participants and asked them about their experiences.

Figure 2. (A) The OpenStreetMap (OSM)-generated virtual environment containing some notable landmarks from (B) the real world.
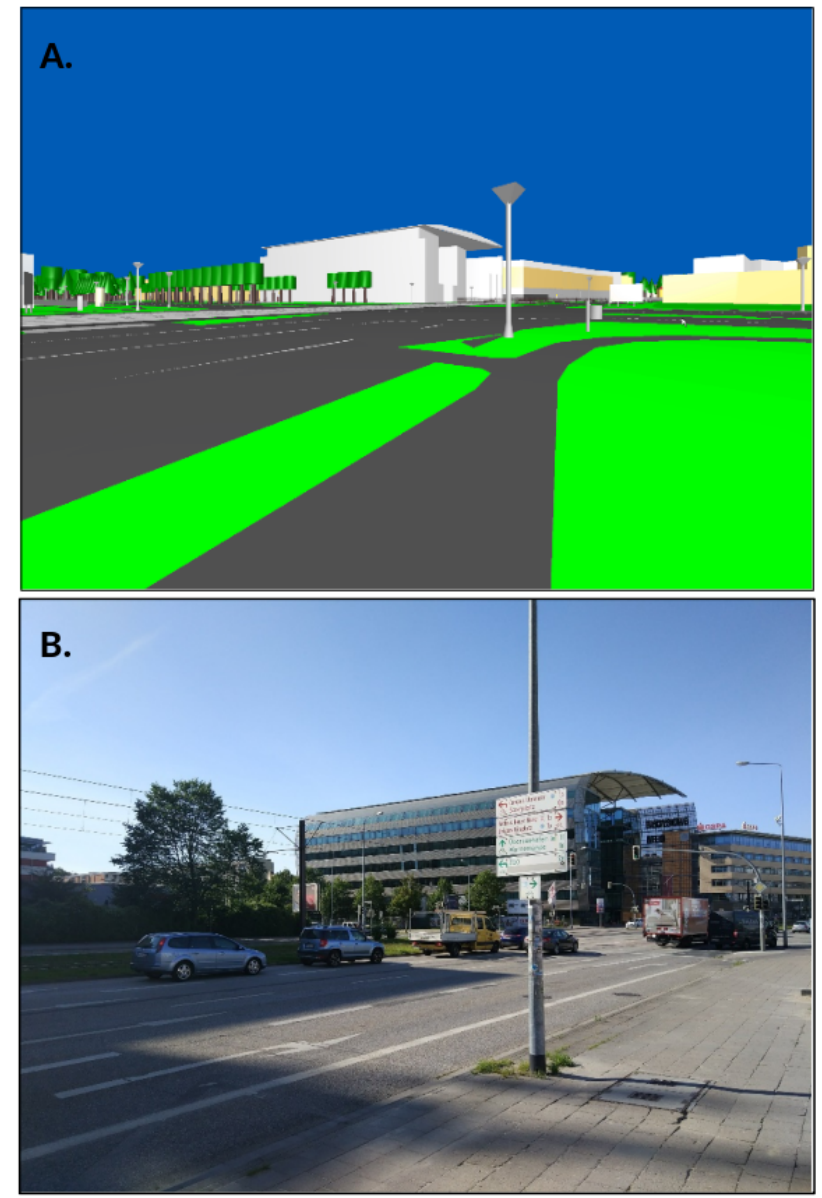

\section{Recruitment and Eligibility}

Participants were recruited in 3 groups: (1) mobile, physically and cognitively healthy, younger (18-40 years of age) adults; (2) mobile, physically healthy older [60-85 years of age; Mini-Mental State Examination (MMSE) scores $\geq 28$ ] adults, including cognitively healthy older adults without memory complaints and cognitively healthy older adults with subjective cognitive decline (SCD) in the absence of any clinical evidence of cognitive impairment; and (3) physically healthy older adults with diagnosed MCI or mild dementia due to Alzheimer disease (60-85 years of age; MMSE 15-27). People with dementia and cognitively healthy older adults are recruited from the memory clinic of the University Medicine, Rostock, while the healthy young adults are recruited from within the University of Rostock student community. Exclusion criteria for all groups include other neurological conditions besides dementia, an inability to understand task instructions and questionnaire items, and deaf-mutism and blindness.

As the focus of this feasibility study was on cognitively healthy older adults and people with dementia, 9 cognitively healthy older participants (5/9 women, 4/9 men; $6 / 9$ with SCD; mean age 70 years, SD 4.40; MMSE mean 29, SD 0.70) and 4 people with dementia (2/4 women, $2 / 4$ men; mean age 78 years, SD 2.30; MMSE mean 20.50, SD 7.54) have been included so far. Of the 9 cognitively healthy older participants, 4 participants (2/4 women, 2/4 men) were randomly assigned to the experimental group. Informed consent was given by all participants.

\section{Study Procedure and Data Collection}

Participants were guided along a path in the VR environment (Figure 3). Afterward, they were set back to the starting location 
and asked to walk the same path again, this time unguided. For half of the healthy young or older subjects (the experimental group), phases of disorientation were induced by changing landmarks or decision points in the VR environment (Figure 4) while subjects were required to walk the path on their own. The changes were (1) moving a landmark from one intersection to the next intersection, (2) adding a decision point (ie, an intersection), (3) blocking a road, or (4) moving the goal indicator to a different location. Overall, 5 locations have been manipulated. For the patients with dementia, the environment was not changed, as we assume that these participants would show phases of disorientation already without such changes due to existing cognitive deficits. Based on the experience with the first patient with dementia, we adapted the route for the other patients by shortening it due to earlier observed fatigue while navigating the route (Figure 3 ).

Figure 3. Map of the routes of (A) cognitively healthy older participants and (B) patients with dementia. Red crosses denote locations where the environment is changed in the experimental run. The environment is unchanged for the patients with dementia; however, the route is shortened (image: Google Maps).

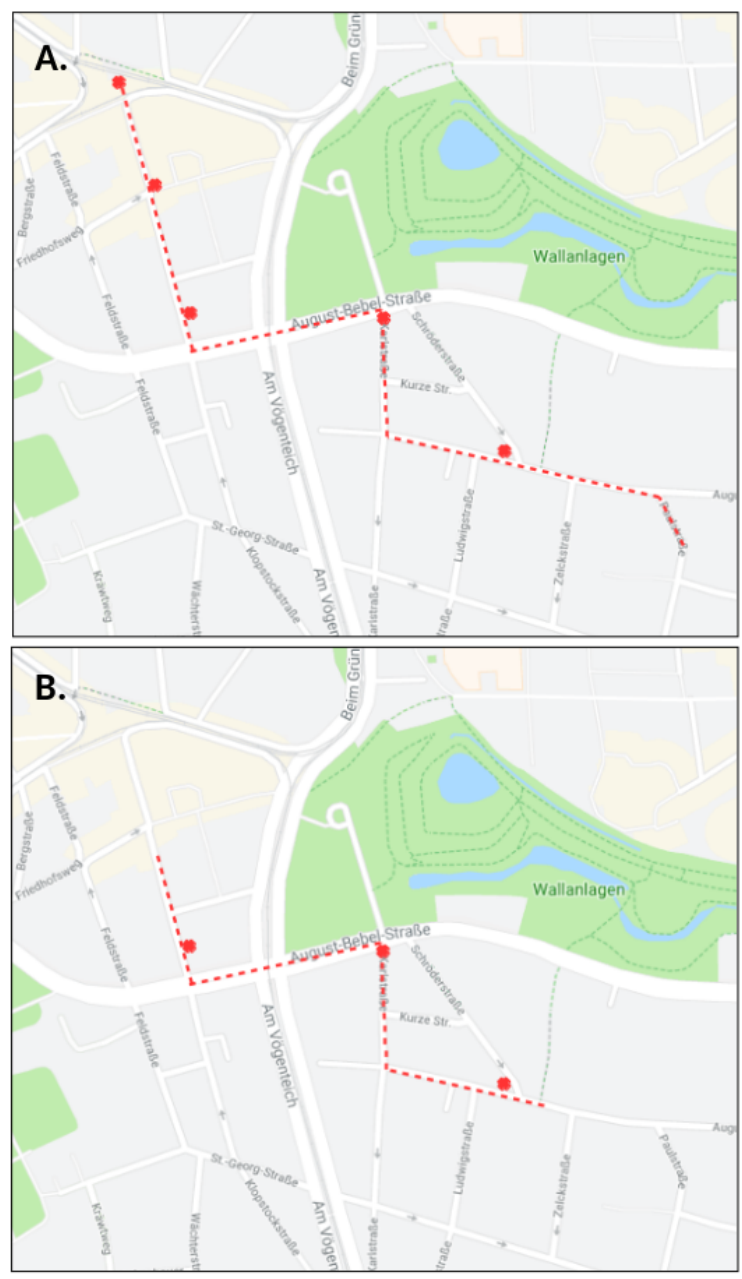


Figure 4. Example of changes in the environment to induce disorientation. (A) Original environment shown in the guided walk (note the red landmark at the far end of the road, to the right). (B) Manipulated environment used in the experimental run; in this case, the landmark is moved to a different intersection.
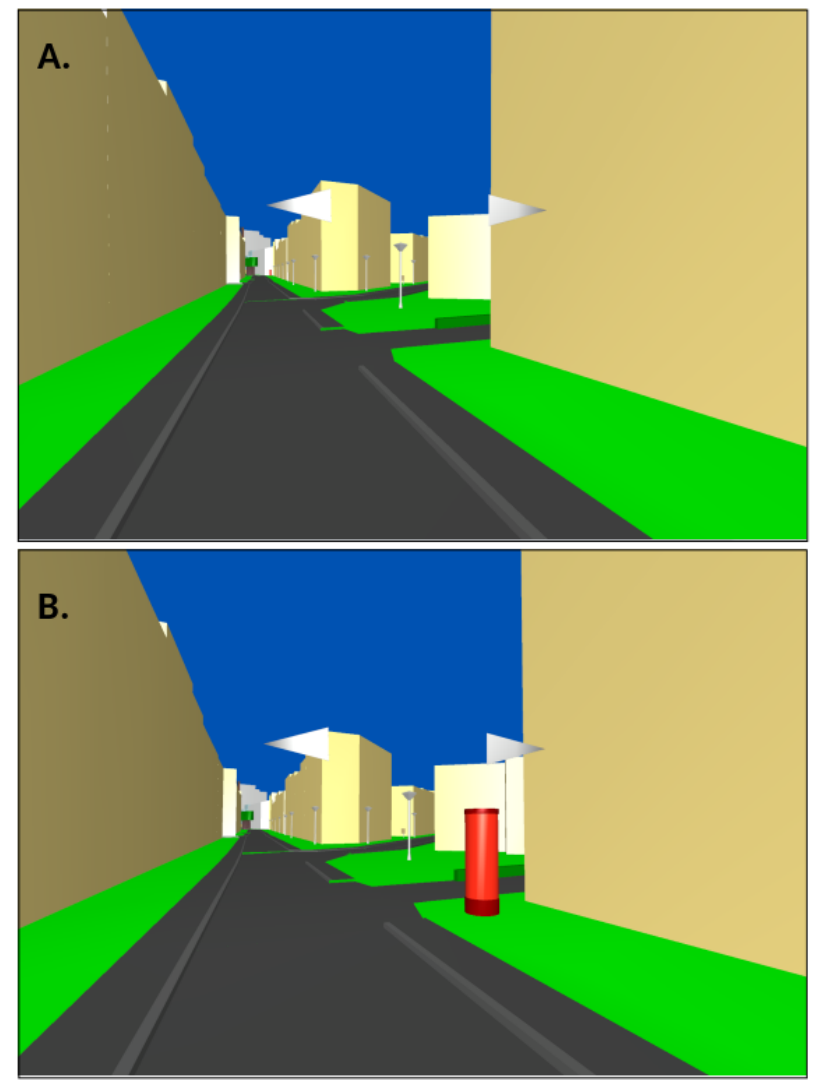

The participants were familiarized with the depicted city center by briefly showing them a map, such that problems in wayfinding will be due to disorientation instead of exploration in an unknown environment. In addition to recording kinematic and kinetic gait parameters as provided by the GRAIL system, participants are also equipped with 3 wearable sensors on the left wrist, right ankle, and chest, each of which contain a 3-axes accelerometer and 3-axes gyroscope sampled with $64 \mathrm{~Hz}$. Additionally, the chest sensor records an electrocardiogram (ECG; $1024 \mathrm{~Hz}$ ), and the wrist sensor records electrodermal activity (EDA; $32 \mathrm{~Hz}$ ). Wearable sensor data and data provided by the GRAIL system are synchronized by an event-based mechanism (ie, participants perform a distinctive movement at the beginning of the recording, which can be easily located in all sensors) and are resampled to $100 \mathrm{~Hz}$. All wearable sensors have been used in previous studies [6,30] and validated [31-33].

After the orientation task, participants filled out the igroup Presence Questionnaire (IPQ) [34], a questionnaire on the functionality and realism of the interaction with the VR environment, as well as questions regarding engagement in the study, hobbies and activities, technical device usage, and demographics. Additionally, participants provided answers to open questions on (1) problems that occurred in controlling the direction, (2) suggestions for improving the controlling mechanism, (3) which properties in the VR they used for orientation, (4) orientation problems they had, and (5) suggestions for enabling better self-orientation in the VR environment. Table 1 displays the experimental procedure in phases. 
Table 1. Experimental procedure for the cognitively healthy older participants $(n=9)$ and patients with dementia $(n=4)$. The patient group followed the procedure of the control group.

\begin{tabular}{|c|c|c|c|}
\hline \multicolumn{2}{|c|}{ Phase } & Experimental group $(n=4)$ & Patients with dementia $(n=4)$ and control group $(n=5)$ \\
\hline 1 & $\begin{array}{l}\text { Preparation } \\
(90 \mathrm{~min})\end{array}$ & \multicolumn{2}{|c|}{$\begin{array}{l}\text { Study information, informed consent, assessment of physical and cognitive status, blood draw, fixing of markers and } \\
\text { electrodes, and practice walking on treadmill }\end{array}$} \\
\hline 2 & $\begin{array}{l}\text { Task } 1 \\
(20 \mathrm{~min})\end{array}$ & \multicolumn{2}{|l|}{ Learning the route: accompanied walk (route: Figure 3) } \\
\hline 3 & $\begin{array}{l}\text { Task } 2 \\
(20 \mathrm{~min})\end{array}$ & $\begin{array}{l}\text { Autonomous navigation } \\
\text { (modified environment) }\end{array}$ & $\begin{array}{l}\text { Autonomous navigation } \\
\text { (unchanged environment) }\end{array}$ \\
\hline 4 & $\begin{array}{l}\text { Questionnaires } \\
\text { (20 min) }\end{array}$ & \multicolumn{2}{|c|}{ Presence, navigation, orientation, experience with technical devices } \\
\hline
\end{tabular}

\section{Randomization}

Randomization of the healthy younger and older participants into the experimental or control group was carried out using the program Research Randomizer (Social Psychology Network) [35]. In contrast, the patients with dementia are only assigned to the control group (ie, with the adapted route), as we expect a sufficient number of episodes of disorientation in people with MCI or dementia even without interfering with their environment.

\section{Behavior Annotation}

An offline annotation procedure was applied to the video data recorded during the orientation task, for assessing the observable orientation behavior of the participants using the ELAN 5.8 tool (The Language Archive) [36]. As a coding scheme, we used an adequate adaption of the coding scheme provided by Yordanova et al [30]. The same scheme has been used in the SiNDeM field study [6]. This coding scheme was developed both by domain experts and assistive systems designers, based on interviews, video logs, data from a systematic literature review, and concepts from existing ontologies, for the purpose of providing assistance to people with dementia during their outdoor mobility. Hence, it covers aspects of orientation behavior that are beyond the scope of wayfinding in our VR setup (eg, behaviors associated with attention to traffic). For this reason, we adapted the coding scheme to capture exactly those behaviors that are obtainable within our virtual reality setup.
Specifically, to identify instances of disorientation, we annotated when participants show wandering behavior (ie, nongoal-directed walk), communication behavior (ie, asking for help when disoriented), topological orientation (ie, trying to orient themselves based on the surrounding environment), or spatial orientation (ie, trying to orient themselves based on landmarks). In addition, different types of errors that are associated with disoriented behavior were annotated (ie, initiation, realization, sequence, and completion errors). The annotations are being evaluated based on the level of agreement between annotators (ie, interrater reliability in terms of Cohen kappa [37]).

\section{Ethical Approval}

This study has been reviewed and approved by the Ethics Commission of the University Medicine Rostock (Approval number: A 2019-0062).

\section{Outcome Measures}

The study is estimated to run until the end of 2021. The outcome measures to be collected are included in Table 2. However, for this pilot study, we focused on the feasibility and usability (level of immersion, perceived control of the gait system) as primary outcomes, and on measures of motion variations (walking speed), physiological variations (heart rate, skin conductance response), and spatial disorientation (frequency of occurrence) as secondary outcomes.

Table 2. Study outcome measures.

\begin{tabular}{|c|c|c|c|}
\hline Outcome Measure & Measurement & Modality & Status \\
\hline Feasibility and usability & Level of immersion, usability feedback & $\begin{array}{l}\text { igroup Presence Questionnaire } \\
\text { (IPQ), usability questionnaire }\end{array}$ & Ongoing \\
\hline Heart rate variability & Rate of change in heart rate & Electrocardiographic sensor & Ongoing \\
\hline Skin conductance & Rate of change in electrodermal response & Electrodermal activity sensor & Ongoing \\
\hline Gait variability & Incidences of change in gait pattern & Gait capturing system of the GRAIL & Ongoing \\
\hline Accelerometry & Incidences of change in motion pattern & Accelerometers & Ongoing \\
\hline Apolipoprotein E4 status & $\begin{array}{l}\text { Presence of the variants Apo-E2, -E3, and -E4 } \\
\text { in the blood samples }\end{array}$ & $7.5 \mathrm{ml}$ blood samples & Ongoing \\
\hline
\end{tabular}




\section{Data Analysis}

Analysis of both the quantitative and qualitative data collected during the course of the study will take place in accordance with predetermined analysis plans; however, for this feasibility study with a limited sample size, we reported basic descriptive statistics (mean and standard deviation as well as frequencies) applied to the quantitative and qualitative data for evaluation purposes using $\mathrm{R}$ statistical software (version 3.6.0; R Core Team).

\section{Results}

\section{Immersiveness of the Virtual Environment}

All participants could complete the experiment. Responses to the IPQ informed us that the cognitively healthy older participants perceived an above-average degree of immersion; group mean item scores (between 1 and 7, where 7 means highest perceived presence/involvement/realism) were 4.60 for presence, 3.92 for involvement, and 4.42 for realism. The patients with dementia, on the other hand, while reporting lower mean scores relative to the cognitively healthy older participants, still perceived a considerable degree of immersion, with group mean item scores of 3.63 for presence, 3.31 for involvement, and 2.60 for realism. Of the 13 participants, only 1 (7\%) of the participants reported simulator sickness.

\section{Inducing Disorientation Through the Manipulation of the Virtual Environment}

Our setup was viable in inducing instances of disorientation. We observed an average of 21.40 instances of disorientation for the cognitively healthy older participants in the control group and 36.50 instances for the cognitively healthy older participants in the experimental group. For the patients with dementia, an average of 37.50 instances of disorientation was observed. A number of these instances of disorientation were observed either at points where the virtual environment was manipulated or at subsequent points afterward, where the participants had to reorient themselves due to the altered virtual environment (Figure 4). This amounted to a good proportion of the data being annotated as disoriented. Furthermore, regarding properties used for orientation, participants mentioned the landmark shown in Figure 4, houses, intersections, and trees.

\section{Comfortability With the Walking Pattern Change due to our Navigation Mechanism}

Participants' responses to the usability questionnaire show that the control over the chosen direction in the VR environment was perceived as functional for both the cognitively healthy older participants and patients with dementia (eg, easy to learn; participants were able to move to where they wanted at their own pace), and adequately naturalistic. Table 3 shows the answer scores on the questionnaire items regarding usability and navigation control. When asked about problems that occurred, only $2(22 \%)$ of the 9 cognitively healthy older participants mentioned initial difficulty with controlling the direction of movement, while $1(25 \%)$ of the 4 patients with dementia mentioned that it felt unusual. Of the 9 cognitively healthy older participants, $2(22 \%)$ also mentioned that the right and left movement felt a little rapid. Additionally, in the case of the first patient with dementia sampled, we observed early fatigue while navigating the route, leading to an adaptation of the patient's route (Figure 3). Also, due to a temporary technical fault at the time of recording, we could not obtain gait information for the first patient with dementia sampled. However, all other data were collected for this patient, and complete data could be collected for the 3 subsequent patients with dementia sampled.

Table 3. Questionnaire regarding the usability of controlling movement in the virtual-reality environment for the cognitively healthy older participants $(\mathrm{n}=9$; group mean score) and patients with dementia ( $\mathrm{n}=4$; group mean score). The scale ranged from 1 (fully disagree) to 7 (fully agree).

\begin{tabular}{lll}
\hline Questionnaire item & $\begin{array}{l}\text { Cognitively healthy older } \\
\text { participants (n=9), mean score }\end{array}$ & $\begin{array}{l}\text { Patients with dementia (n=4), mean score } \\
\text { 1. Learning to navigate was easy. }\end{array}$ \\
$\begin{array}{ll}\text { 2. After a while, I did not have to think about how to navigate. } \\
\text { 3. I was able to move where I wanted. }\end{array}$ & 4.3 & 3.0 \\
4. I was able to move how I wanted & 5.8 & 3.6 \\
5. I was able to stop at a specific place when I wanted. & 4.9 & 3.0 \\
6. I did not feel limited in my freedom of movement. & 5.9 & 4.0 \\
7. I felt tired after navigating. & 5.8 & 3.3 \\
8. Navigation felt natural. & 3.3 & 2.5 \\
\hline
\end{tabular}

\section{Measuring Motion and Physiological Parameters}

Variations in walking speed, heart rate, and skin conductance response were observed among our pilot participants. Figures $5 \mathrm{~A}, \mathrm{~B}$, and $\mathrm{C}$, respectively, show a sample of the recorded walking speed, accelerometry, heart rate variability, and skin conductance response amplitude for a participant in the control group (where the environment was not manipulated), a participant in the experimental group (where the environment was manipulated, as described above), and for a patient with dementia (where the environment was not manipulated). Relative decrease in motion (walking speed and accelerometry) and an increase in heart rate variability and skin conductance response amplitude can be observed during instances of disorientation. 
Figure 5. Sample of motion and physiological data showing variations in walking speed, accelerometry, heart rate, and skin conductance of participants occurring during instances of disorientation (green bars in the first row) from the unguided walk for (A) an older control participant (environment not manipulated), (B) an older experimental participant (environment was manipulated), and (C) a patient with dementia (environment not manipulated).

A.

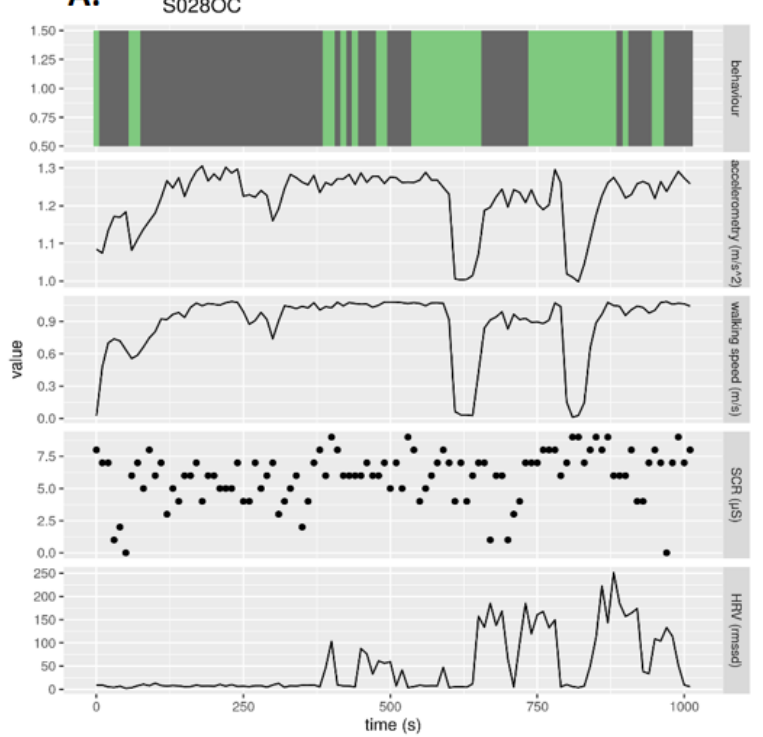

B.

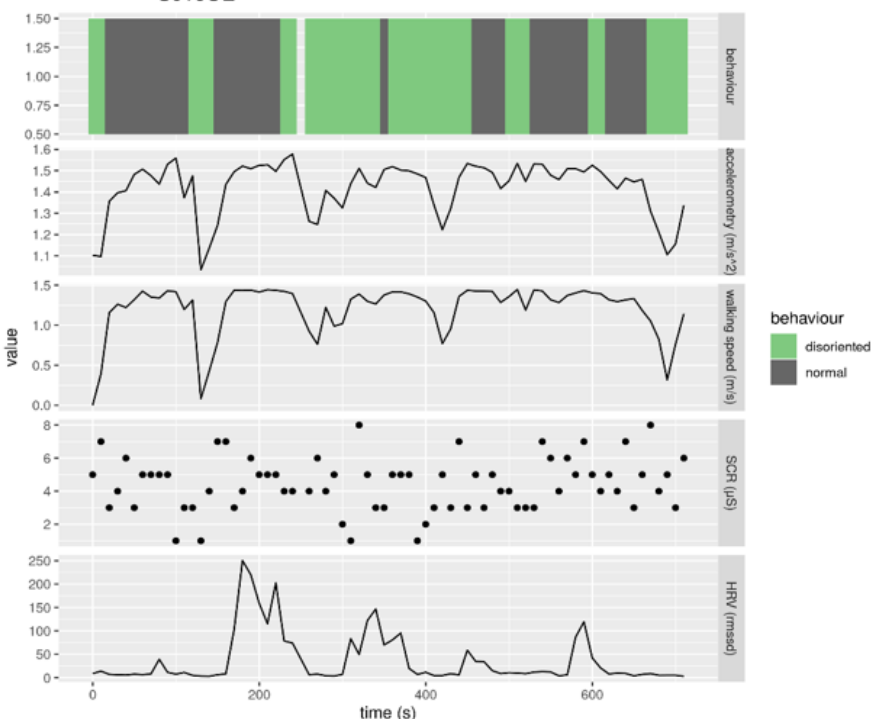

C.

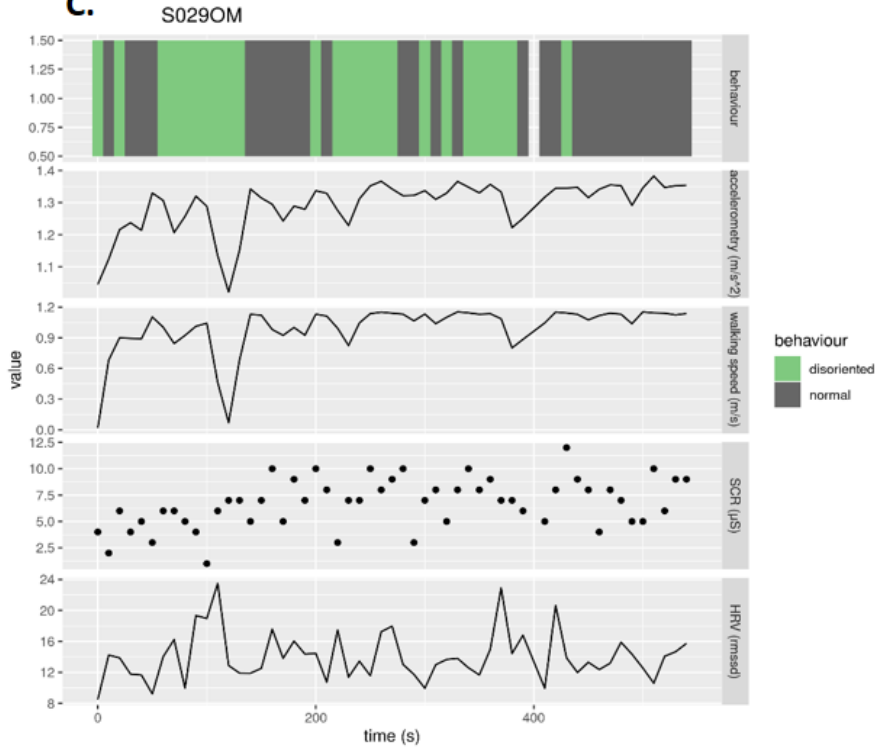

\section{Discussion}

In this paper, we presented the design for a study investigating the effect of spatial disorientation on physical motion and physiological features, as well as the initial outcomes of the pilot sample. The combined usage of a fully instrumented treadmill, wearable sensors, and an adequately immersive VR system to investigate real-time disorientation among older participants and patients with dementia during active navigation is, to the best of our knowledge, unprecedented. Previous studies that investigated spatial orientation [38-40] and navigation memory $[20,41]$ have relied mostly on VR systems in which navigation or interaction with the VR environment was passively based on the use of control objects (eg, joystick, mouse). This, however, further limits the ecological validity of such setups, as the locomotion aspect of real-world navigation was apparently lacking.
Our patient and cognitively healthy older participant dyad reported a noticeably varying degree of immersion. While the older healthy participant group reported a higher level of immersion [42], the patient group reported a relatively lower level of immersion compared to the cognitively healthy older participant group. However, this is not surprising as we also expect cognitive and perceptual abilities to play a significant role in the evaluation of the VR setup, as people with dementia are known to experience visuoperceptual difficulties [43,44], which may influence this judgment. Nonetheless, participants' responses to the usability part of the questionnaire indicated an overall confidence that our setup is effective in investigating manifestations of disorientation among cognitively healthy older adults and people with dementia. Furthermore, the first patient with dementia sampled experienced fatigue while navigating the route (akin to the finding of Behrens et al [27]), which suggests that dual-task conditions can be mentally exhausting among older participants. Therefore, this effect could be 
exacerbated by the increased difficulty of multitasking as a result of cognitive deficits [45]. Hence, we adapted the route of the patients by shortening it relative to the original route.

Considering the number of instances of spatial disorientation, we confirmed our expectation of finding more disorientation events among the participants in the experimental group (changed environment) compared to the participants in the control group (unchanged environment). This preliminary observation gives credence to the validity of our setup in inducing the target behavior of disorientation. We also observed that the patients with dementia expressed a considerable amount of disorientation. This was the case even though the environment remained unchanged, thereby indicating that moments of disorientation accruing to cognitive deficits can also be reliably observed among patients with dementia in our setup. The variations in motion and physiological data observed among our pilot participants illustrates that we are able to adequately obtain the relevant motion and physiological parameters within our approach. As building situation-adaptive devices for supporting navigation among people with dementia relies on the adequate detection of disorientation [6], our setup therefore provides a promising approach to acquiring the needed data.

We acknowledge that there are multiple alternatives to using the GRAIL system for the goal of investigating the effect of spatial disorientation on gait in a lab environment. An alternative to projecting the VR to a screen would be to use a VR headset, like the Oculus Rift (Facebook Inc) or the Samsung Gear VR (Samsung Electronics). A main advantage of the GRAIL over the Oculus Rift and Samsung Gear VR lies in the relative ease of use, safety, and closeness to reality for our study sample, which consists of cognitively healthy older adults and people with dementia who may not be as apt as younger participants at learning to navigate with a VR headset. To participate in the navigation task on the GRAIL, the participant walks freely on the treadmill without any headset or hand gear and observes the virtual environment as one normally would in a real-life situation. In contrast, with the Oculus Rift and Samsung Gear $\mathrm{VR}$, a remarkable difference to the real-world situation is observed the moment one has to put on a headset and navigate with the use of controllers. Additionally, such devices can quickly cause simulator sickness, especially if participants have to move through the environment and when synchronization of head movement and VR movement is not optimal [46]. In this study, simulator sickness was only reported by 1 of the participants so far. Moreover, virtual reality games [such as serious games for dementia care (SGDC)] in which participants interact with the virtual environment using their body movements in the absence of controllers have also reported positive effects on patients' mental and physical health [47]; these include improvement in memory and motivation, through the performance of mental and physical activities that are carried out while using various physical motions.

A major experience reported by a few of the participants, which also serves as a limitation to the current study, was the fact that control over left/right movement felt somewhat challenging. Possible alternatives to the current direction control mechanism used in this study include using a game controller to choose directions [19], or leaning in the respective direction [48]. However, we expect that this would be perceived as even more unrealistic in terms of how well the experimental setup models the real-world situation in which we are very much interested, as this would require movements that are not representative of real-world locomotion. For instance, Kizony et al [19] acknowledged that the combination of the joystick and treadmill may have posed an additional challenge to the older adults, although no discomfort was reported. This could have been further confirmed if participants were asked about their experience using structured measures such as the IPQ and usability questionnaires as employed in this study. Nonetheless, usability and immersion in VR studies remains an open topic. Further studies replicating the setup employed in this study could serve to provide further testing and data for evaluating this setup. Omnidirectional treadmills $[49,50]$ (that allow free movement in all directions) could be a promising alternative for this purpose. However, such systems are still research prototypes and are not commercially available.

In conclusion, our GRAIL setup allows us to collect a rich dataset: most prominently, the motion capturing system can be used to assess spatio-temporal gait parameters (eg, walking speed). Results from this feasibility study suggest that our setup is sufficient in investigating sensor-derived features of spatial disorientation, even in patients with dementia, in a safe and controlled environment that is comparable to the real world. This is evident in the fact that we observed a considerable amount of disorientation among our participants, which also corresponded to the sensor data and questionnaire responses. Based on the full data set, in the future, we will focus on training machine learning classifier models for discriminating instances of disorientation from moments of orientation, with the aim of coming up with a relevant feature set for developing an interventional device. This classifier subsequently will be tested with real-world data (ie, perform transfer of learning). This feasibility study encourages further investigations on the possibility of more robust real-time detection of spatial disorientation, with the aim of coming up with adequate situation-aware interventions.

\section{Acknowledgments}

The GRAIL was funded by the DFG (German Research Foundation), grant number INST 264/137-1 FUGG. The study is also partly funded through the European Regional Development Fund (EFRE), reference number TBI-V-1-100-VBW-035. The funders had no role in study design, data collection and analysis, decision to publish, or preparation of the manuscript. We would like to thank the following people: Johann Bauer, Cindy Rikert, and Marie-Luise Ewald for developing the VR environment application; Anne Klostermann and Charlotte Hinz for conducting the experiments with the pilot subjects; Jonas Töpfer for annotating the videos; and Deborah Sonnenberg for patient recruitment. 


\section{Authors' Contributions}

COA and SL contributed to the conception of the work, acquisition and analysis of the data, and wrote substantial parts of the manuscript. COA reviewed and adapted the annotation scheme used for the study. TK, SJT, SL, and COA provided substantial contributions to the conception and design of the work and the acquisition, analysis, and interpretation of data for the work. TK, SJT, SL, and COA participated in drafting the work, revising it critically for important intellectual content, and approved the version to be published; these authors agree to be accountable for all aspects of the work in ensuring that questions related to the accuracy or integrity of any part of the work are appropriately investigated and resolved.

\section{Conflicts of Interest}

None declared.

\section{References}

1. Kaye J, Matteck N, Hayes T, Austin D, Dodge H. P3-089: Community life withdrawal with MCI progression. 2012 Jul 01 Presented at: Alzheimer 's Association International Conference; July 14 - 19, 2012; Vancouver, British Columbia p. P483-P483. [doi: 10.1016/j.jalz.2012.05.1308]

2. Wettstein M, Wahl H, Shoval N, Oswald F, Voss E, Seidl U, et al. Out-of-home behavior and cognitive impairment in older adults: findings of the SenTra Project. J Appl Gerontol 2015 Feb;34(1):3-25. [doi: 10.1177/0733464812459373] [Medline: 25548086]

3. Glass TA, de Leon CM, Marottoli RA, Berkman LF. Population based study of social and productive activities as predictors of survival among elderly Americans. BMJ 1999 Aug 21;319(7208):478-483 [FREE Full text] [doi:

10.1136/bmj.319.7208.478] [Medline: 10454399]

4. Hughes TF, Flatt JD, Fu B, Chang CH, Ganguli M. Engagement in social activities and progression from mild to severe cognitive impairment: the MYHAT study. Int Psychogeriatr 2013 Apr;25(4):587-595 [FREE Full text] [doi: 10.1017/S1041610212002086] [Medline: 23257280]

5. Teipel S, Babiloni C, Hoey J, Kaye J, Kirste T, Burmeister OK. Information and communication technology solutions for outdoor navigation in dementia. Alzheimers Dement 2016 Jun;12(6):695-707 [FREE Full text] [doi:

10.1016/j.jalz.2015.11.003] [Medline: 26776761]

6. Schaat S, Koldrack P, Yordanova K, Kirste T, Teipel S. Real-Time Detection of Spatial Disorientation in Persons with Mild Cognitive Impairment and Dementia. Gerontology 2020;66(1):85-94. [doi: 10.1159/000500971] [Medline: 31362286]

7. Buracchio T, Dodge HH, Howieson D, Wasserman D, Kaye J. The trajectory of gait speed preceding mild cognitive impairment. Arch Neurol 2010 Aug;67(8):980-986 [FREE Full text] [doi: 10.1001/archneurol.2010.159] [Medline: 20697049]

8. Allali G, Annweiler C, Blumen HM, Callisaya ML, De Cock A, Kressig RW, et al. Gait phenotype from mild cognitive impairment to moderate dementia: results from the GOOD initiative. Eur J Neurol 2016 Mar;23(3):527-541 [FREE Full text] [doi: 10.1111/ene.12882] [Medline: 26662508]

9. Jayakody O, Breslin M, Srikanth VK, Callisaya ML. Gait Characteristics and Cognitive Decline: A Longitudinal Population-Based Study. J Alzheimers Dis 2019;71(s1):S5-S14. [doi: 10.3233/JAD-181157] [Medline: 30958358]

10. Callisaya ML, Blizzard L, Schmidt MD, Martin KL, McGinley JL, Sanders LM, et al. Gait, gait variability and the risk of multiple incident falls in older people: a population-based study. Age Ageing 2011 Jul;40(4):481-487. [doi: 10.1093/ageing/afr055] [Medline: 21628390]

11. Westmoreland D, Krell RW, Self BP. Physiological responses to the Coriolis illusion: effects of head position and vision. Aviat Space Environ Med 2007 Oct;78(10):985-989. [doi: 10.3357/asem.2010.2007] [Medline: 17955949]

12. Tamura A, Iwamoto T, Ozaki H, Kimura M, Tsujimoto Y, Wada Y. Wrist-Worn Electrodermal Activity as a Novel Neurophysiological Biomarker of Autonomic Symptoms in Spatial Disorientation. Front. Neurol 2018 Dec 4;9. [doi: 10.3389/fneur.2018.01056]

13. Cushman LA, Stein K, Duffy CJ. Detecting navigational deficits in cognitive aging and Alzheimer disease using virtual reality. Neurology 2008 Sep 16;71(12):888-895 [FREE Full text] [doi: 10.1212/01.wnl.0000326262.67613.fe] [Medline: $\underline{18794491]}$

14. Craig M, Wolbers T, Harris MA, Hauff P, Della Sala S, Dewar M. Comparable rest-related promotion of spatial memory consolidation in younger and older adults. Neurobiol Aging 2016 Dec;48:143-152 [FREE Full text] [doi: 10.1016/j.neurobiolaging.2016.08.007] [Medline: 27689512]

15. McGuinness B, Barrett SL, Craig D, Lawson J, Passmore AP. Attention deficits in Alzheimer's disease and vascular dementia. J Neurol Neurosurg Psychiatry 2010 Feb;81(2):157-159. [doi: 10.1136/jnnp.2008.164483] [Medline: 20145028]

16. Silveri MC, Reali G, Jenner C, Puopolo M. Attention and memory in the preclinical stage of dementia. J Geriatr Psychiatry Neurol 2007 Jun;20(2):67-75. [doi: 10.1177/0891988706297469] [Medline: 17548775]

17. Mirahadi SS, Khatoonabadi SA, Fekar Gharamaleki F. A Review of Divided Attention Dysfunction in Alzheimer's Disease. Middle East J Rehabil Health Stud 2018 Jun 26;5(3). [doi: 10.5812/mejrh.64738]

18. Nebes RD, Brady CB. Focused and Divided Attention in Alzheimer's Disease. Cortex 1989 Jun;25(2):305-315. [doi: 10.1016/s0010-9452(89)80045-0] 
19. Kizony R, Zeilig G, Krasovsky T, Bondi M, Weiss PL, Kodesh E, et al. Using virtual reality simulation to study navigation in a complex environment as a functional-cognitive task; A pilot study. J Vestib Res 2017;27(1):39-47. [doi: 10.3233/VES-170605] [Medline: 28387691]

20. Ijaz K, Ahmadpour N, Naismith SL, Calvo RA. An Immersive Virtual Reality Platform for Assessing Spatial Navigation Memory in Predementia Screening: Feasibility and Usability Study. JMIR Ment Health 2019 Sep 03;6(9):e13887 [FREE Full text] [doi: 10.2196/13887] [Medline: $\underline{31482851]}$

21. Moreno A, Wall KJ, Thangavelu K, Craven L, Ward E, Dissanayaka NN. A systematic review of the use of virtual reality and its effects on cognition in individuals with neurocognitive disorders. Alzheimers Dement (N Y) 2019;5:834-850 [FREE Full text] [doi: 10.1016/j.trci.2019.09.016] [Medline: 31799368]

22. Kober SE, Wood G, Hofer D, Kreuzig W, Kiefer M, Neuper C. Virtual reality in neurologic rehabilitation of spatial disorientation. J Neuroeng Rehabil 2013 Feb 08;10:17 [FREE Full text] [doi: 10.1186/1743-0003-10-17] [Medline: 23394289]

23. van den Bogert AJ, Geijtenbeek T, Even-Zohar O, Steenbrink F, Hardin EC. A real-time system for biomechanical analysis of human movement and muscle function. Med Biol Eng Comput 2013 Oct;51(10):1069-1077 [FREE Full text] [doi: 10.1007/s11517-013-1076-z] [Medline: 23884905]

24. de Rooij IJM, van de Port IGL, Visser-Meily JMA, Meijer JG. Virtual reality gait training versus non-virtual reality gait training for improving participation in subacute stroke survivors: study protocol of the ViRTAS randomized controlled trial. Trials 2019 Jan 29;20(1):89 [FREE Full text] [doi: 10.1186/s13063-018-3165-7] [Medline: $\underline{30696491]}$

25. de Kruijff LGM, Prins M, van der Krans A, Hoencamp R, van der Wurff P. Combat-related foot injuries: impact on gait and functional outcome. J R Army Med Corps 2018 Sep;164(5):322-327. [doi: 10.1136/jramc-2017-000870] [Medline: 29436477]

26. Biffi E, Costantini C, Ceccarelli SB, Cesareo A, Marzocchi GM, Nobile M, et al. Gait Pattern and Motor Performance During Discrete Gait Perturbation in Children With Autism Spectrum Disorders. Front Psychol 2018;9:2530 [FREE Full text] [doi: 10.3389/fpsyg.2018.02530] [Medline: $\underline{\text { 30618953] }}$

27. Behrens M, Mau-Moeller A, Lischke A, Katlun F, Gube M, Zschorlich V, et al. Mental Fatigue Increases Gait Variability During Dual-task Walking in Old Adults. J Gerontol A Biol Sci Med Sci 2018 May 09;73(6):792-797. [doi: 10.1093/gerona/glx210] [Medline: 29077783]

28. Knerr T. OSM2World. 2019. URL: http://osm2world.org/ [accessed 2020-06-07]

29. Sloot LH, van der Krogt MM, Harlaar J. Self-paced versus fixed speed treadmill walking. Gait Posture 2014;39(1):478-484 [FREE Full text] [doi: 10.1016/j.gaitpost.2013.08.022] [Medline: 24055003]

30. Yordanova K, Koldrack P, Heine C, Henkel R, Martin M, Teipel S, et al. Situation Model for Situation-Aware Assistance of Dementia Patients in Outdoor Mobility. J Alzheimers Dis 2017;60(4):1461-1476. [doi: 10.3233/JAD-170105] [Medline: 29060937]

31. Härtel S, Gnam J, Löffler S, Bös K. Estimation of energy expenditure using accelerometers and activity-based energy models_-validation of a new device. Eur Rev Aging Phys Act 2010 Dec 2;8(2):109-114. [doi: 10.1007/s11556-010-0074-5]

32. Kapp D, Schaaff K, Ottenbacher J, Heuer S, Bachis S. Isolating the effects of emotional stimuli in EDA measurements: White paper 2017. URL: https://www.movisens.com/de/produkte/eda-sensor/ [accessed 2020-07-07]

33. Bachis S, Ottenbacher J. Validity of ecgMove R-peak detection: White paper 2017. URL: https://www.movisens.com/de/ produkte/ekg-sensor/ [accessed 2020-07-07]

34. Schubert T, Friedmann F, Regenbrecht H. The Experience of Presence: Factor Analytic Insights. Presence: Teleoperators and Virtual Environments 2001 Jun;10(3):266-281. [doi: 10.1162/105474601300343603]

35. Urbaniak G, Plous S. Research Randomizer (Version 4.0). 2013. URL: https://www.randomizer.org/ [accessed 2018-12-12]

36. Wittenburg P, Brugman H, Russel A, Klassmann A, Sloetjes H. ELAN: a professional framework for multimodality research. 2006 Presented at: 5th International Conference on Language Resources and Evaluation (LREC 2006); 2006; Genoa p. 1556-1559. [doi: 10.1093/oxfordhb/9780199571932.013.019]

37. Cohen J. A Coefficient of Agreement for Nominal Scales. Educational and Psychological Measurement 1960 Apr 01;20(1):37-46. [doi: 10.1177/001316446002000104]

38. da Costa RQM, Pompeu JE, de Mello DD, Moretto E, Rodrigues FZ, Dos Santos MD, et al. Two new virtual reality tasks for the assessment of spatial orientation Preliminary results of tolerability, sense of presence and usability. Dement Neuropsychol 2018;12(2):196-204 [FREE Full text] [doi: 10.1590/1980-57642018dn12-020013] [Medline: 29988338]

39. Delahaye M, Lemoine P, Cartwright S, Deuring G, Beck J, Pflueger M, et al. Learning aptitude, spatial orientation and cognitive flexibility tested in a virtual labyrinth after virtual stress induction. BMC Psychol 2015;3(1):22 [FREE Full text] [doi: 10.1186/s40359-015-0080-5] [Medline: 26146558]

40. Kimura K, Reichert JF, Olson A, Pouya OR, Wang X, Moussavi Z, et al. Orientation in Virtual Reality Does Not Fully Measure Up to the Real-World. Sci Rep 2017 Dec 22;7(1):18109 [FREE Full text] [doi: 10.1038/s41598-017-18289-8] [Medline: 29273759]

41. Burgess N, Trinkler I, King J, Kennedy A, Cipolotti L. Impaired allocentric spatial memory underlying topographical disorientation. Rev Neurosci 2006;17(1-2):239-251. [doi: 10.1515/revneuro.2006.17.1-2.239] [Medline: 16703955]

42. Tichon J, Banks J. Virtual reality exposure therapy: 150-degree screen to desktop PC. Cyberpsychol Behav 2006 Aug;9(4):480-489. [doi: 10.1089/cpb.2006.9.480] [Medline: 16901251] 
43. Mendez MF, Tomsak RL, Remler B. Disorders of the visual system in Alzheimer's disease. J Clin Neuroophthalmol 1990 Mar;10(1):62-69. [Medline: 2139054]

44. Kimoto A, Iseki E, Ota K, Murayama N, Sato K, Ogura N, et al. Differences in responses to the Rorschach test between patients with dementia with Lewy bodies and Alzheimer's disease -from the perspective of visuoperceptual impairment. Psychiatry Res 2017 Nov;257:456-461. [doi: 10.1016/j.psychres.2017.08.038] [Medline: 28837937]

45. Cohen J, Verghese J. Gait and dementia. Handb Clin Neurol 2019;167:419-427. [doi: 10.1016/b978-0-12-804766-8.00022-4] [Medline: 31753146]

46. Nichols S, Patel H. Health and safety implications of virtual reality: a review of empirical evidence. Applied Ergonomics 2002 May;33(3):251-271. [doi: 10.1016/s0003-6870(02)00020-0]

47. Breton Z, Zapirain BG, Zorrilla AM. KiMentia: Kinect based tool to help cognitive stimulation for individuals with dementia. : IEEE; 2012 Presented at: 2012 IEEE 14th International Conference on e-Health Networking, Applications and Services; 10-13 October 2012; Beijing, China. [doi: 10.1109/healthcom.2012.6379430]

48. Tregillus S, Zayer M, Folmer E. Handsfree Omnidirectional VR Navigation using Head Tilt. New York, NY: The Association for Computing Machinery; 2017 Presented at: 2017 CHI Conference on Human Factors in Computing Systems (CHI '17); May 2017; New York p. 4063-4066. [doi: 10.1145/3025453.3025521]

49. Iwata H. The Torus Treadmill: realizing locomotion in VEs. IEEE Comput. Grap. Appl 1999 Nov 01;19(6):30-35. [doi: 10.1109/38.799737]

50. Souman JL, Giordano PR, Schwaiger M, Frissen I, Thümmel T, Ulbrich H, et al. CyberWalk. ACM Trans. Appl. Percept 2011 Nov;8(4):1-22. [doi: 10.1145/2043603.2043607]

\section{Abbreviations}

AD: Alzheimer disease

ATD: assistive technology device

BPM: beats per minute

ECG: electrocardiography

EDA: electrodermal activity

GRAIL: Gait Real-time Analysis Interactive Lab

IPQ: igroup Presence Questionnaire

MCI: mild cognitive impairment

MMSE: Mini-Mental State Examination

OSM: OpenStreetMap

SiNDeM: Situation-Aware Navigation Assistance for Dementia Patients using Causal Behavior Models

VR: virtual reality

Edited by G Eysenbach; submitted 27.02.20; peer-reviewed by E Park, K Ho, E Vanegas; comments to author 29.06.20; revised
version received 28.08.20; accepted 02.09.20; published 08.10.20
Please cite as:
Amaefule CO, Lüdtke S, Kirste T, Teipel SJ
Effect of Spatial Disorientation in a Virtual Environment on Gait and Vital Features in Patients with Dementia: Pilot Single-Blind
Randomized Control Trial
JMIR Serious Games 2020;8(4):e18455
URL: $\underline{\text { https://games.jmir.org/2020/4/e18455 }}$
doi: $\underline{10.2196 / 18455}$
PMID: $\underline{3030436}$

(C) Chimezie O Amaefule, Stefan Lüdtke, Thomas Kirste, Stefan J Teipel. Originally published in JMIR Serious Games (http://games.jmir.org), 08.10.2020. This is an open-access article distributed under the terms of the Creative Commons Attribution License (https://creativecommons.org/licenses/by/4.0/), which permits unrestricted use, distribution, and reproduction in any medium, provided the original work, first published in JMIR Serious Games, is properly cited. The complete bibliographic information, a link to the original publication on http://games.jmir.org, as well as this copyright and license information must be included. 